\title{
A Review of Technology for Contact Protection of Remediation Manipulators (WHC Issue 39)
}

\author{
Siegfried Thunborg \\ Intelligent Systems Department I \\ Sandia National Laboratories \\ Albuquerque, NM 87185
}

\begin{abstract}
Remediation of waste from Underground Storage Tanks (UST) at Hanford will require the use of large remotely controlled equipment. Inherent safety methods need to be identified and incorporated into the retrieval system to prevent contact damage to the UST or to the remediation equipment. This report discusses the requirements for an adequate protection system and reviews the major technologies available for inclusion in a damage protection system.
\end{abstract}

The report proposes that adequate reliability of a protection system can be achieved through the use of two fully-independent subsafety systems. Safety systems technologies reviewed were Force/Torque Sensors, Overload Protection Devices, Ultrasonic Sensors, Capacitance Sensors, Controller Software Limit Graphic Collision Detection, and End Point Tracking. A relative comparison between retrieval systems protection technologies is presented. 


\section{CONTENTS}

$\begin{array}{ll}\text { INTRODUCTION } & 1\end{array}$

$\begin{array}{ll}\text { SYSTEM REQUIREMENTS } & 1\end{array}$

TECHNOLOGY 2

FORCE/TORQUE SENSOR 2

OVERLOAD PROTECTION DEVICES 3

ULTRASONIC SENSOR 4

CAPACITANCE SENSORS 4

CONTROLLER SOFTWARE LIMITS 6

GRAPHIC COLLISION DETECTION 6

END POINT TRACKING $\quad 8$

TECHNOLOGY COMPARISON SUMMARY 9

SUMMARY 11

$\begin{array}{ll}\text { REFERENCES } & 13\end{array}$ 


\section{DISCLAIMER}

This report was prepared as an account of work sponsored by an agency of the United States Government. Neither the United States Government nor any agency thereof, nor any of their employees, make any warranty, express or implied, or assumes any legal liability or responsibility for the accuracy, completeness, or usefulness of any information, apparatus, product, or process disclosed, or represents that its use would not infringe privately owned rights. Reference herein to any specific commercial product, process, or service by trade name, trademark, manufacturer, or otherwise does not necessarily constitute or imply its endorsement, recommendation, or favoring by the United States Government or any agency thereof. The views and opinions of authors expressed herein do not necessarily state or reflect those of the United States Government or any agency thereof. 


\section{DISCLAIMER}

Portions of this document may be illegible in electronic image products. Images are produced from the best available original document. 


\author{
A Review of Technology for Contact \\ Protection of Remediation Manipulators
}

(WHC Issue 39)

\title{
Introduction
}

Remediation of waste from the Underground Storage Tanks (UST) at Hanford will require the use of large remotely operated equipment. At times, this equipment must operate within tanks containing considerable In-TankHardware (ITH) and in tanks where the condition of the metal tank liner is unknown and could be severely degraded. Visibility in the tanks during retrieval operations through use of remote video systems can be very limited. Any damage that occurs to the retrieval system or to the tank during remediation operations has the potential to be very costly, both in terms of repairing the damage and in terms of the down time realized during repairs and during incident investigations and resolution.

Operator awareness cannot be relied upon to insure there are no damage-causing contacts between all parts of retrieval equipment and all tank features. Inherent safety methods need to be identified and incorporated into the retrieval system. Depending on the type of system chosen for deployment, there are a variety of safety systems that can be incorporated to insure safe operation. These range from mechanical limit devices to software limits to sensor subsystems. Some of these approaches are dependent on the type of kinematics chosen for the retrieval arm while others are not. In most cases, these safety features can be coupled together to achieve a redundant safety approach.

This report will discuss the requirements for an adequate protection system and review the major technologies available for inclusion in a damage protection system.

\section{System Requirements}

One acceptable method of insuring adequate reliability of a protection system is to base the system on at least two fully independent subsafety systems. Fully independent requires that there are no components common to both systems. For instance, position reporting should not come from the same encoder for both systems or computing for both systems should not be done in the same computer. While maximum reliability desires fully independent systems, practicability sometimes may bend the rule. Any deviation from two independent systems should be supported by a reliability analysis of the actual system, which can be a costly and time-consuming action.

It is anticipated that in-tank retrieval equipment will be designed to be as lightweight as possible, but strong enough to span the $75 \mathrm{ft}$. tanks. Even so, such a design will be difficult to stop quickly due to its mass. Further, it is 
anticipated that the system will be designed so lightweight that it will have significant static and dynamic flexure to the extent that it must be included in any computations predicting arm position. Consequently, any safety system should provide a warning of a collision in order to provide time for a safe stop of the retrieval equipment.

Any sensor-based safety system that requires a sensor within the tank must be cognizant of the environment within the tank during waste dislodging operations. For instance, water jet cutting systems can result in a spray which can deposit a coating on the sensors and impede their proper operation. Consequently, sensor-based safety systems face a difficult environment and provision must be made to insure reliable operation in the tank environment throughout all operations.

A potential problem for any model-based safety system is that it must be assumed that the tank will contain obstacles unknown to the world model. Early detection of these obstacles through sensors or by periodic visual surveys is critical.

Any arm protection system should include provisions for a "Watchdog" monitoring system to insure all systems are operational at all times.

In the selection of an adequate safety system, it should be remembered that complexity can work against reliability. Consequently, a system requiring many sensors, much wiring or multiplexing should be rated lower than a simple system.

In some respects these are contradictory requirements for a protection system. The safest way to prevent damage to a system is to prevent contact, yet some retrieval operations may require that the waste removal tool maintain contact with the waste even as the rest of the retrieval arm is prevented from contact with the waste or other items in the tank. Consequently, a protection system capable of reconfiguration to meet the application at hand is desirable.

\section{Technology}

A survey of technologies that may be applicable for a protection system has been conducted. Their compatibility with each other, the benefits and limitations of each approach, their operational concepts and potential costs are discussed in detail below and summarized in Fig. 1.

\section{Force/Torque Sensor}

There are several manufacturers of 6 axis Force-Torque $(\mathrm{F} / \mathrm{T})$ sensors which can resolve in real time the 6 force components about any specified orthogonal coordinate system. Operating parameters such as force limits can be modified remotely. Most have a capability to provide an external signal if a set force or torque is exceeded. System costs are on the order of $\$ 10,000$ for conventionally sized systems. A system sized for the retrieval arm with a 
radiation capability would cost much more but no specific data are readily available. However, it is likely that the retrieval arm will require a F/T sensor for other reasons, and the incremental cost of the use of the sensor in a protection system will be zero.

Some of the considerations of this type of sensor for obstacle avoidance are described.

- The F/T sensor will give no warning of a potential contact.

- Since actual contact is required to activate a F/T system, the system must rely on arm compliance to prevent damage during deceleration of the arm. For arm motions of moderate to high speeds, arm compliance may not be adequate to prevent damage.

- A F/T based protection system will primarily protect components downstream from the F/T sensor. The system will not provide adequate whole arm protection.

- A F/T based system will afford limited protection from unknown . obstacles. The only unknown obstacles detected will be those which contact the retrieval arm downstream of the $\mathrm{F} / \mathrm{T}$ sensor.

- A F/T based system can be made nearly impervious to the environment within the tank.

\section{Overload Protection Devices}

Overload Protection Devices (OPD), sometimes known as Breakaway Joints, sense end-of-arm loading and when that loading exceeds a preset value they provide an output signal for system shut down. In addition they provide for a limited amount of deflection to accommodate deacelleration of the system.

OPD's are available from several commercial sources at a cost on the order of $\$ 7500$ for systems sized for conventional robots.

- An OPD based protection system will give no warning of a potential contact.

- An OPD based system will only protect components downstream from the OPD system.

- OPD devices are limited in their ability to protect against torque. By the nature of their design, the allowable torque for a system is interrelated to the allowable $x-y-z$ forces and as a consequence to allow large torque is to allow large $x-y-z$ forces.

- An OPD system will only afford limited protection from unknown obstacles. The only unknown obstacles detected will be those which contact the retrieval arm downstream of the OPD system.

- An OPD based system can be made nearly impervious to the environment within the tank. 


\section{Ultrasonic Sensor}

An ultrasonic system for protection of end-of-arm tooling was successfully demonstrated in the RTDP Demonstration at Westinghouse Hanford in 1991. The system used eight sensors mounted on the sides and front of an end effector to detect obstacles. (References 3 and 4) Eight sensors were used to cover the field of view to the sides and front of the end effector. Each sensor transmitted at $38 \mathrm{k} \mathrm{Hz}$ into a $60^{\circ}$ cone and covered a dynamic range from 5 to $150 \mathrm{~cm}$ with a resolution of $0.2 \mathrm{~mm}$. The system demonstrated was for end of arm protection only and did not offer whole arm protection. No ultrasonic sensor systems for whole arm protection have been developed to date. Such a system would require a multitude of sensors and could quickly become so complex that establishment of system reliability could be a major problem.

Basically, ultrasonic systems just detect objects. The control response to the object can be varied. The simplest control solution is to maintain a safe distance to all obstacles detected. However, there can be occasions where the arm must operate in the immediate vicinity of known obstacles. In this case the control scenario becomes complex in that it requires knowledge of the world to discriminate safe signals from dangerous signals. In the case of flexible robot systems, control is even more complex for the world model knowledge must include flexure and dynamic response of the flexible robot.

- Ultrasonic systems can provide warning of a collision and can detect unknown obstacles in the work area.

- Ultrasonic systems require a prior knowledge of the world and extensive software if retrieval operations require signal discrimination.

- Ultrasonic systems can be seriously affected by the tank environment. Particles in the air or coatings deposited on the sensor will affect sensor output.

\section{Capacitance Sensors}

Capacitance based proximity sensors generate electric fields that completely encompass a robot arm and detect obstacles as they approach from any direction. The distribution of the electric field allows broad coverage of a robot without a large number of sensors. Changes in the electric field are sensed instantaneously, unlike sound based systems which require listening for an echo. The electric field volume is dependent on the shape and size of the sensor electrode. Electric field volume may be considered to be a hemisphere with radius of 10 times the diameter of a circle encompassing the electrode pair. A capacitance measurement is also insensitive to color, texture, and surface orientation of an obstacle. Capacitance sensors are inherently simple and reliable, consisting of two conductive plates with minimal supporting electronics located near the sensing site. 
Because the electric field intensity decreases with distance from the electrodes, a capacitance device is very sensitive to material close to the electrodes. However, if the sensing electrodes are covered with a stable dielectric material, such as Teflon, the electric field properties within the coating can be considered to be constant, and this constant capacitance may be subtracted from the measured sensor reading. In this way, the sensor can be protected from the environment, while still capable of detecting distant objects. The Teflon coating does not, however, protect from erroneous readings as a result of spray deposits from Waste Dislodging Tools. While a spray coating will further distort the signal, the magnitude of the error should not be sufficient to preclude use of capacitance technology during simultaneous operation of a Waste Dislodging Tool. Further developmental testing will be required to evaluate the signal distortion resulting from a thin coating of the waste material.

References 1 and 2 describe development of a capacitance based collision avoidance system. This systems, called a Whole Arm Proximity (WHAP) system has been successfully demonstrated on an articulated robot arm. This system used capacitor sensors of 1 inch diameter and had a usable range of about 10 inches. The SNL technology developed in the WHAP system is currently being transferred to an Industrial source for commercialization.

Capacitance based proximity systems are similar to ultrasonic based proximity systems in that they both only detect obstacles. The control response to the obstacle can be varied. The simplest control solution is to maintain a safe distance to all obstacles. However, there can be occasions where the arm must operate in the immediate vicinity of known obstacles. In this case the control scenario becomes complex in that it requires knowledge of the world to discriminate safe signals from dangerous signals. In the case of flexible robot systems, control is even more complex for the world knowledge must include flexure and dynamic response of the flexible robot.

- Capacitance based systems can provide warning of a collision and can detect unknown obstacles in the work area.

- Capacitance based systems require a prior knowledge of the world and extensive software if retrieval operations require signal discrimination.

- Capacitance based systems can be seriously affected by the tank environment. Particles in the air or coatings deposited on the sensor can affect sensor output. Very concentrated water/salt solutions will tend to act as conductors and sensitivity may be significantly reduced. 


\section{Controller Software Limits}

Most commercial robot Low Level Controllers (LLC) have a capability to limit robot movement through software limits. Work cell limits can be defined and the controller will monitor movements to insure all motions are within the designated work cell. Calculations are made by the LLC on a joint and world basis, which insures that not only will the end point not exceed the work cell limit but the individual joint limits will not either.

- Protection systems based on software limits must account for static deflection and dynamic response when used with highly flexible arms. The easy but inaccurate solution to this problem is to increase the warning zone for potential collisions. The more difficult solution is to account for flexibility in the kinematic model of the arm at the LLC level.

- If the work cell limit is to be defined by hardware position (such as tank walls), a software limit safety system will require accurate position calibration of the retriever arm to the hardware.

- LLC Software Limits protection becomes increasingly difficult for kinematically complex arms or complex work cells. Robot controllers do not have a capability to describe the geometry and obstacles of a complicated work cell. They usually describe the outer limit of the work cell and not zones within the work cell. Safety through software limits will be difficult to implement due to (1) the complexity of the workcell when in-tank-hardware is accounted for, and (2) the need to redefine the workcell as retrieval operations proceed in the tanks.

- A software limit safety system is capable of providing a warning of objects known to be in the work cell but not of unknown objects in the work cell.

- A software limit system is impervious to the environmental conditions in the tank.

\section{Graphic Collision Detection}

Several of the Robot Simulation Packages commercially available offer a model-based collision detection capability. In these systems a 3-D graphical model of the robot work cell is constructed and combined with a correct kinematic model of the robot. Rapid updates of the robot position allow the determination of potential collisions between objects in the work cell and the robot. This system also provides a graphic interface to the operator, which can be used to provide additional safety. For example, prior to the start of a series of programmable operations, the computer compares the desired robot trajectory with the geometric knowledge contained in the world model. Any unsafe trajectory that is detected is reported to the operator via the graphics 
interface. The operator can then modify the proposed trajectory by manipulating the robot in the graphics interface to achieve collision free paths or automatic path planners can be used to plan the path for the operators.

Graphical collision detection systems are not completely independent systems in that they require a fast update of the robot position from an outside source. Typically, that source is the robot position encoders and is provided via the local robot controller at a very fast update rate, usually faster than the information can be used by a 3-D graphics package. In the graphic package, the robot position is calculated at specific times throughout the move. If a large time step is used, the contact between a small object and the robot may be missed. However, proper selection of time step in relation to obstacle size will alleviate this problem. A fast update rate of the graphics package is important for teleoperation of the robot arm. In this situation, collision detection must be near real time to be effective. For instance, a robot arm moving at $1 \mathrm{ft} / \mathrm{sec}$ and with a graphics update of 250 milliseconds would be 3 inches ahead of the graphics image.

3-D graphic packages are available commercially from several sources at a price from $\$ 40 \mathrm{~K}$ to $\$ 100 \mathrm{~K}$ depending on system capability. However, it is anticipated that the waste retrieval arm system will have a 3-D graphics package as part of the Supervisory Control System and utilization of this package for collision detection will be possible. A supervisory control system with collision detection capabilities was demonstrated at Westinghouse/Hanford in 1991, and references 3 and 4 present details of the system used in that demonstration.

- Graphic model-based collision detection systems have a serious complication if the robot is flexible. For highly flexible robots the graphic model of the robot must account for static deflection and dynamic response of the flexible arm if it is to be useful in modelbased collision avoidance strategies.

- Implementation of graphic collision detection systems require knowledge of the kinematic solutions for the robot that were developed by the robot manufacturer for use in their robot controller. Some robot manufacturers may consider this information proprietary.

- Graphic collision detection systems operate independent of the tank environment.

- Graphic systems provide warning of impending collision. Also the distance parameter to notify the operator of an impending collision can be modified through the user interface of most commercial graphic systems.

- These systems require an accurate work cell model with calibration of work cell coordinate system to the robot coordinate system. Objects unknown to the work cell model will not be detected. 


\section{End Point Tracking}

End Point Tracking (EPT) systems usually track a sensor and/or beacon on the robot arm from a beacon and/or sensor mounted on the workcell. Position data taken by the EPT system can then be compared to robot encoder positions from the robot controller to confirm end of arm location. End Point Tracking systems differ from vehicle tracking systems in the degree of accuracy required and in the need to determine 6 degrees of freedom

EPT systems are available commercially from several sources. Commercial systems are usually designed to accurately calibrate robot position data or to track tool position in a small workcell. The most promising commercial system provided position only (no orientation), had a small work volume, and needed recalibration whenever the beam was broken as it could be in a waste tank containing in-tank-hardware. Further development of these commercially available systems would be required to allow their use in the UST application.

ORNL is completing development of a system specifically designed for use in waste retrieval operations. The ORNL system uses a pan and tilt mounted laser and rotating mirrors to scan the interior of the tank. From 4 to 8 sensors mounted on the end of the arm detect the laser and provide a time stamp to allow comparison of laser determined position with robot encoder position as provided by the robot controller. Multiple sensors at the end of a robotic arm allow range determination and provide for beam interruption due to in-tank-hardware.

End point tracking systems provide position/orientation only; they do not determine collision potential. One use for EPT data is to use the data as independent position input to the Collision Detection capability of a 3-D graphic package, such as used in a Supervisory Control System. To independently use the EPT position data for collision detection requires it to have its own world model and computation capability. Consequently, an independent EPT collision detection system can be quite costly.

- End Point Tracking systems offer end of arm or discrete point protection only. However, whole arm coverage could be extrapolated from knowledge of the robot kinematic control solutions. Another possibility is to use EPT technology to track each joint of the robot. No systems currently exist to do independent joint tracking and a system developed for this purpose would be complex enough to require testing to confirm reliability.

- In some waste tanks, the lack of a direct line of site between the EPT transmitter and receiver due to interference of in-tank hardware or parts of the robot arm, or due to degraded atmospheric conditions inside the tank can reduce system functionality. 
- Dispersal of the laser beam by the in-tank environment and thus the failure to be detected by the sensors will result in intermittent inoperability of the system.

- End Point Tracking systems when combined with a 3-D graphic package can warn of impending collision but will not detect unknown obstacles.

\section{Technology Comparison Summary}

Fig. 1 presents a relative comparison between retrieval system protection technologies. 
Protection Technology

\begin{tabular}{|c|c|c|c|c|c|c|c|c|c|c|}
\hline Capability & $\begin{array}{l}\text { Force } \\
\text { Torque } \\
\text { Sensor }\end{array}$ & $\begin{array}{l}\text { Overload } \\
\text { Protection } \\
\text { Device }\end{array}$ & $\begin{array}{l}\text { Ultrasonic } \\
\text { Sensor } \\
\text { (End of } \\
\text { Arm) } \\
\end{array}$ & $\begin{array}{c}\text { Ultrasonic } \\
\text { Sensor } \\
\text { (Whole } \\
\text { Arm) } \\
\end{array}$ & $\begin{array}{c}\text { Capacitance } \\
\text { Sensor } \\
\text { (End of } \\
\text { Arm) }\end{array}$ & $\begin{array}{c}\text { Capacitance } \\
\text { Sensor } \\
\text { (Whole } \\
\text { Arm) }\end{array}$ & $\begin{array}{l}\text { Controller } \\
\text { Software } \\
\text { Limits }\end{array}$ & $\begin{array}{c}\text { Graphic } \\
\text { Collision } \\
\text { Detection }\end{array}$ & $\begin{array}{l}\text { End Point } \\
\text { Track } 1 \\
\text { (End of } \\
\text { Arm) } \\
\end{array}$ & $\begin{array}{l}\text { End Point } \\
\text { Track } \\
\text { (Whole } \\
\text { Arm) }\end{array}$ \\
\hline $\begin{array}{c}\text { Whole Arm } \\
\text { Protection } \\
\text { Ability }\end{array}$ & No & No & No & Yes & No & Yes & $\overline{\text { Yes }}$ & Yes & No & Yes \\
\hline $\begin{array}{l}\text { Unknown } \\
\text { Obstacle } \\
\text { Detection } \\
\text { Ability }\end{array}$ & No & No & $\begin{array}{c}\text { Partial } \\
\text { End-of } \\
\text { Arm } \\
\text { Only }\end{array}$ & Yes & $\begin{array}{c}\text { Partial } \\
\text { End-of } \\
\text { Arm } \\
\text { Only }\end{array}$ & Yes & No & No & No & No \\
\hline $\begin{array}{l}\text { Collision } \\
\text { Warning } \\
\text { Ability }\end{array}$ & No & No & $\begin{array}{c}\text { Partial } \\
\text { End-of } \\
\text { Arm } \\
\text { Only }\end{array}$ & Yes & $\begin{array}{c}\text { Partial } \\
\text { End-of } \\
\text { Arm } \\
\text { Only }\end{array}$ & Yes & $\begin{array}{c}\text { Partial } \\
\text { No-Unknown } \\
\text { Objects }\end{array}$ & $\begin{array}{c}\text { Partial } \\
\text { No-Unknown } \\
\text { Objects }\end{array}$ & $\begin{array}{c}\text { Partial } \\
\text { No- } \\
\text { Unknown } \\
\text { Objects }\end{array}$ & Yes \\
\hline $\begin{array}{c}\text { Electro/ } \\
\text { Mechanical } \\
\text { Complexity }\end{array}$ & $\begin{array}{l}\text { Extremely } \\
\text { Simple }\end{array}$ & $\begin{array}{l}\text { Extremely } \\
\text { Simple }\end{array}$ & Simple & Complex & Simple & $\begin{array}{l}\text { Somewhat } \\
\text { Complex }\end{array}$ & Simple & Simple & $\begin{array}{l}\text { Somewhat } \\
\text { Complex }\end{array}$ & $\begin{array}{c}\text { Very } \\
\text { Complex }\end{array}$ \\
\hline $\begin{array}{l}\text { Affected by } \\
\text { Tank } \\
\text { Environment }\end{array}$ & No & No & Yes & Yes & Yes & $\overline{Y e s}$ & No & No & Yes & Yes \\
\hline $\begin{array}{l}\text { Arm Flexibility } \\
\text { Compensation }\end{array}$ & $\begin{array}{c}\text { Partial } \\
\text { End-of } \\
\text { Amm } \\
\text { Only }\end{array}$ & $\begin{array}{c}\text { Partial } \\
\text { End-of } \\
\text { Arm } \\
\text { Only } \\
\end{array}$ & $\begin{array}{c}\text { Partial } \\
\text { End-of } \\
\text { Anm } \\
\text { Only } \\
\end{array}$ & Yes & $\begin{array}{c}\text { Partial } \\
\text { End-of } \\
\text { Arm } \\
\text { Only } \\
\end{array}$ & Yes & $\begin{array}{c}\text { Possible but } \\
\text { not } \\
\text { demonstrated }\end{array}$ & $\begin{array}{c}\text { Possible but } \\
\text { not } \\
\text { demonstrated }\end{array}$ & $\begin{array}{l}\text { Partial } \\
\text { End-of- } \\
\text { Arm } \\
\text { Only }\end{array}$ & $\begin{array}{c}\text { Yes. but } \\
\text { not } \\
\text { demonstrated }\end{array}$ \\
\hline $\begin{array}{l}\text { Degree of } \\
\text { Complex } \\
\text { Computing } \\
\text { Support } \\
\text { Required } \\
\end{array}$ & None & None & Small & Large & Large & Medium & Large & Large & Medium & Large \\
\hline
\end{tabular}

Note: ${ }^{1}$ It is assumed End Point Tracking has its own world model and computational ability.

\section{Technology Comparison}

Fig. 1 


\title{
Summary
}

Computer based protection systems, such as Controller Software Limits or Graphic Collision Detection Systems, offer the greatest overall protection but they require precise world models. Precise models can be difficult to establish initially and must be continually updated as waste (or intank-hardware) is removed from the tank or is stored temporarily in the tank. For flexible arms, computer based systems require compensation for static and dynamic flexure of the arm in the world model. This compensation is computationally intensive and could be extremely difficult to be completed at the desired rate. However, there are simplifying assumptions that can be made to speed up this process and, in fact, some commercially available Robot Simulation Packages have a capability in flexure compensation. Further, flexure compensation is a technology area under development by the Department of Energy. Without this compensation, the safe separation distance to obstacles must be increased to a point where close retrieval operations are extremely difficult or impossible to do safely.

Safety of computer based systems can be improved by the addition of sensor based systems such as proximity or force sensors to protect from unknown obstacles and/or to compensate for the lack of knowledge in the world model. Sensor based systems will be hard to rely on totally because of their susceptibility to erroneous output resulting from environmental conditions in the waste tank and because of the difficulty of using them to provide whole arm protection.

Retrieval operations in a waste tank can take many forms, sometimes requiring contact with the waste and sometimes not, sometimes requiring operation close to an obstacle and sometimes not. All of this occurs in a world where the geometry changes as waste is removed. Definition of a completely safe protection system is extremely difficult and such a system could be excessively complicated and expensive. All of the technologies discussed herein have deficiencies in some areas. For these reasons a versatile protection system, capable of reconfiguration, is desirable. For instance, for close or contact retrieval operations, mainline protection could be from a force sensor. Whereas in non-contact operations the force sensor may be a secondary line of protection to a computer based system.

There are many ways individual protection systems could be combined to offer maximum overall protection to the retrieval arm and waste tank, but all will have problems as can be determined by the discussions herein. One possible system is as follows:

\author{
Mainline Protection (2 independent technologies) \\ Graphic Collision Detection \\ Controller Software Limits \\ Secondary Protection \\ Force Sensor \\ Capacitive Sensor (WHAP)
}


A difficulty with this solution would be to insure independence of the two mainline protection systems. Arm position data and/or world model calculations

should not be from the same source. One possible solution to independent position data is to confirm position data to the Graphic Collision Detection system with End Point Tracking data. Another is to require redundant position encoders on the retrieval arm. Another complication is the necessity to account for arm flexure either by flexure calculation for the arm or by increasing the safe separation distance to obstacles. If the arm configuration and/or tank configuration become too complex to describe in an adequate world model for a Controller Software Limits protection system, consideration should be given to the use of another independent Graphic Collision Detection System.

The Secondary Protection System would use sensors and would operate real time. It would serve to detect problems not sensed in the mainline protection system such as unknown obstacles.

In summary, protection of the waste retrieval system is not a simple problem. It will require the use of multiple technologies to achieve adequate protection. Once a protection system is proposed or established, it should be subjected to a reliability analysis of the system and its components to confirm adequate protection reliability. 


\section{References;}

1. J. L. Novak and J. T. Feddema, "A Capacitance Based Proximity Sensor for Whole Arm Obstacle Avoidance," Proc. IEEE Int. Conf. on Robotics and Automation, Nice, France, 1992.

2. J. L. Novak and J. T. Feddema, "A Capacitance Based Proximity Sensor for Whole Arm Obstacle Avoidance," American Nuclear Soc., Fifth Topical Mtg. on Robotics and Remote Systems, Knoxville, TN, April 1993.

3. W. Drotning, B. Christensen, and S. Thunborg, "Graphical Model Based Control of Intelligent Robot Systems," IEEE Control Systems, August, 1992.

4. B. K. Christensen and L. M. Desjarlais, "A Graphical Interface for Robotic Remediation of Underground Storage Tanks, Proc. IEEE Conference on Visualization, October, 1990. 


\section{DISTRIBUTION}

No. of

Copies

2 Oak Ridge National Laboratories Attn: Bill Hamel

2 Oak Ridge National Laboratories Attn: Barry Burks

2 Pacific Northwest Laboratories Attn: Dave Bennett

2 Pacific Northwest Laboratories Attn: Mark Evans

5 Westinghouse Hanford Co.

Attn: Pete Gibbons

J. Yount

W. Jaquish

L. McDaniel

A. Williams

10 Westinghouse Hanford Co.

Attn: Eric Shen

1 Lawrence Livermore National Laboratories Attn: Eric Grasz

2 FEMP

Attn: Brack Hazen

Don Herman

2 West Savannah River

Attn: Clyde Ward

Randy Singer

1 WINCO

Attn: Bruce Wilding

1 Los Alamos National Laboratories

Attn: R. Hollen

1 DOE - HQ

Lin Yarbrough 


\section{DISTRIBUTION}

No. of

Copies
1 MS 0322 P. J. Eicker, 2100
1 MS 0949 R. W. Harrigan, 2102
1 MS 0951 P. A Erickson, 2103
1 MS 0949 P. A. Molley, 2111
1 MS 0951 D. R. Strip
1 MS 0952 R. D. Palmquist, 2151
1 MS 0952 B. R. Davies, 2151
1 MS 0952 W. E. Ford, 2151
1 MS $0952 \quad$ R. J. Anderson, 2151
1 MS 0952 D. J. Miller, 2151
60 MS 0952 D. S. Horschel, 2161
1 MS 0952 W. M. Davidson, 2161
1 MS 0952 J. M. Griesmeyer, 2161
1 MS 0952 M. J. McDonald, 2161
1 MS 0952 S. E. Slezak, 2161
1 MS 0952 K. Kwok, 2161
1 MS $1006 \quad$ P. Garcia, 2171
1 MS 1007 A. T. Jones, 2172
1 MS 9018 Central Technical Files, 8523-2
7 MS 0899 Technical Library, 13414
1 MS 0619 Technical Publications, 13416
10 MS 0100 Document Processing for DOE/OSTI, 7613-2 